\title{
Planning for PV plant performance monitoring by means of unmanned aerial systems (UAS)
}

\author{
F. Grimaccia $\cdot$ M. Aghaei $\cdot$ M. Mussetta $\cdot$ \\ S. Leva $\cdot$ P. Bellezza Quater
}

Received: 18 July 2014/ Accepted: 23 October 2014/Published online: 12 November 2014

(C) The Author(s) 2014. This article is published with open access at Springerlink.com

\begin{abstract}
The sustainable use of renewables will represent a key challenge in the near future, and relative energy management operations will play a crucial role in energy efficiency and savings for future generations. The operation and maintenance of energy systems are a very high valuable activity to prevent energy losses, and a correct monitoring can detect in advance equipment degradation guaranteeing good performance over time. Present research strives to find out possibility of unmanned aerial vehicle (UAV) use in monitoring applications for energy production sites and to investigate effects of this novel method on energy management procedures. Furthermore, investigation about novel approaches in cooperative inspection of real photovoltaic (PV) plants was carried out by light UAVs and utilize the global positioning system to find out
\end{abstract}

Published in the Special Issue 8th AIGE Conference (Italian Association for Energy Management).

F. Grimaccia $(\bowtie) \cdot$ M. Aghaei · M. Mussetta · S. Leva Department of Energy, Politecnico di Milano, 20156 Milan, Italy e-mail: francesco.grimaccia@polimi.it

M. Aghaei

e-mail: mohammadreza.aghaei@polimi.it

M. Mussetta

e-mail: marco.mussetta@polimi.it

S. Leva

e-mail: sonia.leva@polimi.it

F. Grimaccia · M. Aghaei - M. Mussetta - S. Leva

Department of Energy, Politecnico di Milano, 20133 Milan, Italy

P. B. Quater

Nimbus S.r.l., 10040 Lombardore, TO, Italy

e-mail: p.bellezza@nimbus.aero the optimum route mapping during the solar PV modules monitoring. The purpose of this work is to propose a reliable, fast and cost effective method for PV plant planning and monitoring by means of UAS technology.

Keywords Unmanned aerial vehicle (UAV) . Photovoltaic (PV) module · Thermal imaging · Operation and maintenance $(\mathrm{O} \& \mathrm{M}) \cdot$ Energy management

\section{Introduction}

The sustainable usage of renewable sources has become an issue which will represent a key challenge in the near future. The increase in demand due to least developed countries and the recovery of global economy promise to foster new research efforts on renewable energy resources, especially in terms of system performance and grid interfacing.

The number of distributed PV plants producing electricity has been significantly increased, and most of the installations are becoming decentralized. Europe itself has experienced one of the largest growths in this sector: in the last five years, the electricity generation by renewable energy sources (RES) in general, and photovoltaic (PV) in particular, increased a lot.

Thus, issues of monitoring and maintaining energy produced from intermittent sources have become of great importance and involves many challenges as efficiency, reliability, safety, and stability: all these aspects can make also advantage of the ability to control and predict energy flows.

Typically, operations, and maintenance can be one of the most effective methods to ensure energy efficiency, safety, reliability, and cost effectiveness [1]. 
Timely inspection in fact is a key factor to recognize degradations and defects of the utilized equipment in many sectors like power transmission line, oil and gas, nuclear and renewable energy itself (photovoltaic, wind, hydropower, etc.).

The PV module analysis methods are an interesting field of research which will involve in the near future active cooperation between academia, laboratories, financial institutions, and manufacturers to define a new paradigm about data collection and accuracy [2].

Recent advances in the aerial industry technology, sensors, and control systems make now possible to utilize unmanned aerial vehicles (UAVs) or systems (UASs) in inspecting and monitoring different energy plants in a cooperative way. Initially, UAVs were introduced just for military purposes. However, in the last decade, UAVs started to appear in many application areas like for example power transmission lines inspection, disaster relief, oil and gas pipelines, ports and off-shoreline security, pollution and environmental monitoring, and so on.

Nevertheless, one of the most significant applications of UAVs is energy equipment monitoring. Typically, they are used in inspection purposes since they present some special advantages like large area coverage, precise imagery, fast detection, high flexibility, light weight, low cost, ability to operate in hostile environments [3].

The main purpose of this study is to investigate UAS applications in energy management with particular attention to solar energy in order to propose a low cost, rapid and reliable method to inspect energy plants, achieve and maintain high performance during operations. In fact, the proposed method can make the process of detection for PV plants quite fast and replicable for many sites. For this purpose, a light UAV was employed in a first experimental study campaign in order to detect PV modules' defects by thermal imaging and visual cameras in Solar Tech lab at Politecnico di Milano university and in a real PV field plant (north of Italy) with $3 \mathrm{MW}$ capacity. In particular, current work concentrates in finding out an optimized monitoring method by using light UAV cooperation in PV modules performance analysis.

The paper is structured in the following four sections. Next section discusses UASs classification and their application in energy sector, taking into account regulatory issues. A third section presents first experimental activities at Solar Tech lab describing the light UAV platform used during the flight tests. In section four, the experimental investigation is described reporting first captured data taken by the UAV. Finally, in "Conclusion" section, we draw some conclusions including a short summary of advantages of the proposed technique.

\section{UAS technology}

\section{UAS classification}

In light of past and present experiences, one way of categorizing the functional capabilities of UAS is not only through different characteristics such as their use (e.g., target and decoy, reconnaissance, combat, logistics, research and development and civil or commercial) but also focusing on other main features. Some UAS in fact are capable to fulfill more than one functionality at the same time while others are designed only to fulfill one specific mission [4].

In the past decade, a rapid development of UAVs has been observed especially in civil sector, for example in monitoring applications such as environmental monitoring, search and rescue operations, pollution monitoring, port and off shoreline security, forest fire detection, and so on [5].

Typically, UAS are also classified for example based on their altitude, range, weight, and size.

Different types of UAS are used for specific operations. Generally, micro- and mini-UAS are utilized in low altitude and uncontrolled airspace. Typically, light weight UAS, which are the most interesting for our scope, are less than $150 \mathrm{~kg}$ and they are appropriate for monitoring tasks in many practical industrial applications. Normally, speed of UAS can vary in a wide range from decades to hundreds of $\mathrm{km} / \mathrm{h}$. However, a UAV with low speed is more useful for inspection purposes, hence in this experimental work Nimbus light UAVs platform has been used due to their flexibility and suitable speed for PV modules monitoring [6].

\section{UAS in energy applications}

Recently, as already mentioned, usage of UAS has widened its application to commercial and energy inspection operations, power transmission line inspection, gas and oil pipeline monitoring. Energy monitoring and forecasting can be very important to reduce production cost of energy and optimize O\&M. UAS are not only suitable for oil and gas pipeline monitoring but also for RES. Some of gas transmission pipeline networks' length can reach to $200,000 \mathrm{~km}$ and require large area coverage. The UAS inspection method may ensure in this context a high level of safety and cost efficiency in pipeline monitoring by mounting suitable cameras, optical and radar sensors on UAS [7].

Control of electric power transmission lines may involve inspection of high voltage insulators and other connecting devices, especially for diagnostic purposes. In the majority of countries, helicopters are used in this context, but they generally cannot stay too close to transmission lines for 


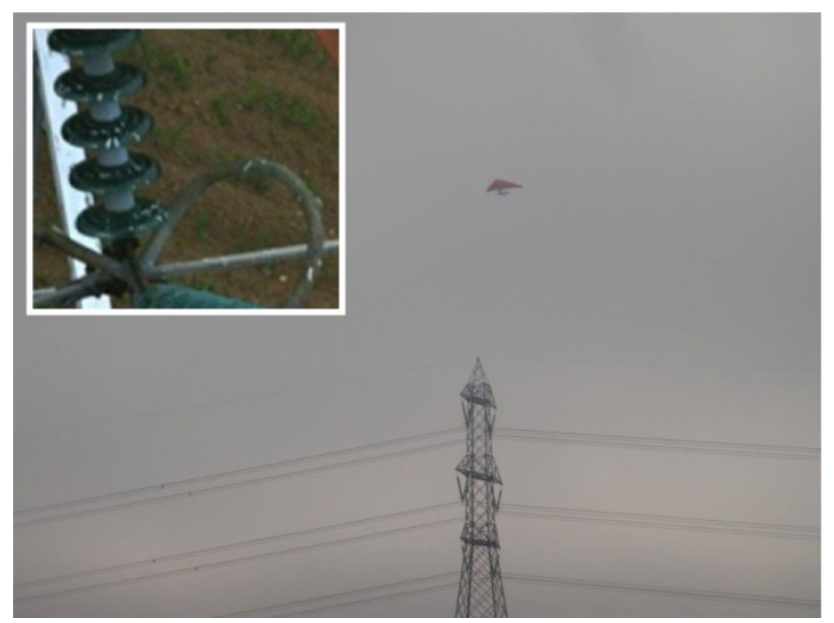

Fig. 1 Example of inspection process of transmission lines performed by Nimbus EosXi UAV in Italy

observation due to noise and disturbance issues [8]. The distance is commonly between 20 and $100 \mathrm{~m}$, depending on the equipment used and at a height of about 10-15 m from the ground. Moreover, utilizing helicopter for power transmission lines inspection is always extremely costly and dangerous in some cases. Therefore, using light UAS can be a reliable and inexpensive alternative to previous methods.

UAS can be suitably employed for power transmission line monitoring by mounted required sensors (hyper-spectral) and cameras (thermal and infrared) to detect many faults, malfunction, and degradation on equipment of power transmission $[9,10]$. Figure 1 shows previous flight inspection test procedure of power line by UAV in Italy. This monitoring has been carried out by EosXi platform from Nimbus, one of the main light UAV manufacturers in the country.

Besides, controlling and monitoring renewable energy systems can led to decrease renewable energy cost also by other activities like forecasting of energy production. Particularly, photovoltaic and wind energy forecasting can help operators to predict the electric balance between power production and supply demand to decrease energy prices. In addition, recently photovoltaic plants have been extended due to developing solar energy in the world. Thus, the inspection procedure requires much more time and as well precise data of defects and faults in PV plants are very necessary to find early solutions [11].

Again there is a great possibility of utilizing light weight UAS in PV plants monitoring due to various advantages such as high flexibility, large area coverage, precise imagery, cost efficiency, fast detection, ability to operate in hostile environments, high technical availability to detect defects by accurate sensors, and special cameras like infrared and thermal models $[12,13]$.
UAS regulation issues

Typically, if we want to move from research to real market applications, it is mandatory to take into account the regulation aspect which becomes fundamental.

There are many regulations for remotely piloted aerial vehicles in different countries. The regulatory and integration aspects regarding the light UAV segment are a key study area [14], even if a lack of a regulatory framework is widespread in many countries. Integration of unmanned systems into the same airspace requires to review current policies, regulations, environmental impact, privacy considerations, standards, and procedures, and recognition of gaps in current RPA (Remote Piloted Aircrafts) technologies. In Italy a lot of work has been already done in this context, and this country has a position of advantages with respect to many other European countries.

ENAC, the Italian Flight Regulation authority, is responsible for regulatory aspects of air transport system and performs monitoring functions related to the enforcement of the adopted rules even in the light unmanned sector starting to deal with this topic many years ago. Nevertheless, nowadays a special regulation has been published in Italy to approve other permission to fly for light UAS [15].

Obviously, there are various factors to issuing permission to fly for UAS. Some significant issues such as builder configuration, reference and standards, system description and features, flying architecture structure, fire protection, data link, description of pilot station, security, flight termination system, flight manual, safety analysis, SW components, hardware issues, pilot acceptance, operations, payload, organization, logistics, configuration control, and flight operation management must be taken into account to obtaining PtF (permit to fly) documentations for light UAS. In current experimental study, a light UAV was used from Nimbus Company for PV panels monitoring in Solar Tech lab.

The Flight Regulation requirements were fulfilled by a small enterprise active in Piedmont which recognized the key points that led to receive multiple Permit to Fly for a light hybrid UAV platforms starting its activity in many research projects.

\section{Experimental study}

In this first investigation, a reliable and cost efficient method is proposed to monitor PV plants by light UAV manufactured in Italy. The experimental study has been carried out at SolarTech Lab at Politecnico di Milano University and also in real PV array field (in north of Italy) with 3 MW capacity. 
Typically, there are many different methods for PV modules monitoring like visual detection, PV parameters measurement, infrared and Thermal Cameras, and so on.

Inspection by sight is the first evaluation of PV modules failures. Moreover, defects in PV modules can be found by measuring the output under standard test conditions (STCTemperature: $25^{\circ}$, Radiation: $1,000 \mathrm{~W} / \mathrm{m}^{2}, \mathrm{AM} 1.5$ ).

Thermal and infrared cameras can be used to detect high temperature regions in the PV module surface and mounted onboard to perform a fast and reliable monitoring task. Therefore, thermography technique can be employed to detect different PV modules defects like for example hot spots, snail trails, and other by using high-resolution thermal or infrared cameras in PV array field [12].

In current experimental research, the difference of inspection procedures in a PV laboratory and a real PV plant has been explored to find out a novel approach to reduce monitoring time and wasted energy. In the next two subsections, these two different application fields are described with relative details.

\section{Solar Tech Lab facility}

The SolarTech lab has been established on the roof of the Department of Energy at Politecnico di Milano University in 2011. Its mission is the experimental investigation of electrical and thermal power generation systems based essentially on solar energy.

The Solar Tech lab integrates 25 independent PV modules which consist of 14 poly-crystalline, five monocrystalline, and four PV-Thermal modules which can be considered as single plants. It should be mentioned that all of the PV modules are fixed toward south by angle of $30^{\circ}$, except two of them which have tunable tilt angles.

During the experimental investigation, 20 PV modules were connected to the low voltage distribution grid through separate micro-inverters to optimize the operating conditions. Structure of PV modules position in the SolarTech lab is shown in Fig. 2.

Various sensors were installed in the Solar Tech Lab to measure solar irradiation, temperature, humidity, and wind parameters (speed/direction). In addition, it should be mentioned that solar irradiation is measured by three different sensors, namely a net radiometer to measure the direct normal irradiance (DNI) and two pyranometers $(2,000 \mathrm{~W} /$ $\mathrm{m}^{2}$ measurement range and $0.3-60 \mu \mathrm{m}, 305-2,800 \mathrm{~nm}$ spectral range) to measure solar diffusion and irradiation [16].

Real PV plant on ground

The real PV plants inspection is very different from PV laboratory monitoring by UAS due to the size of PV plants.

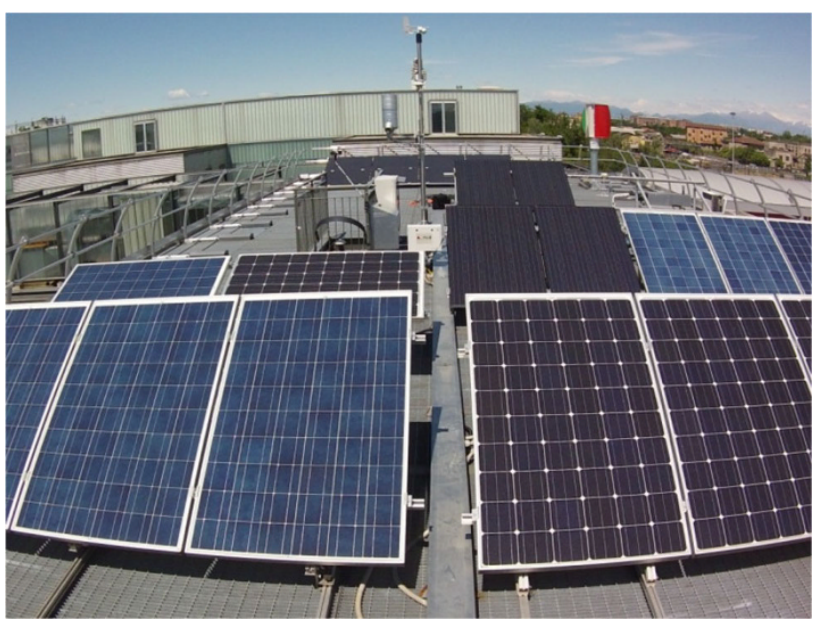

Fig. 2 Solar Tech Lab test field

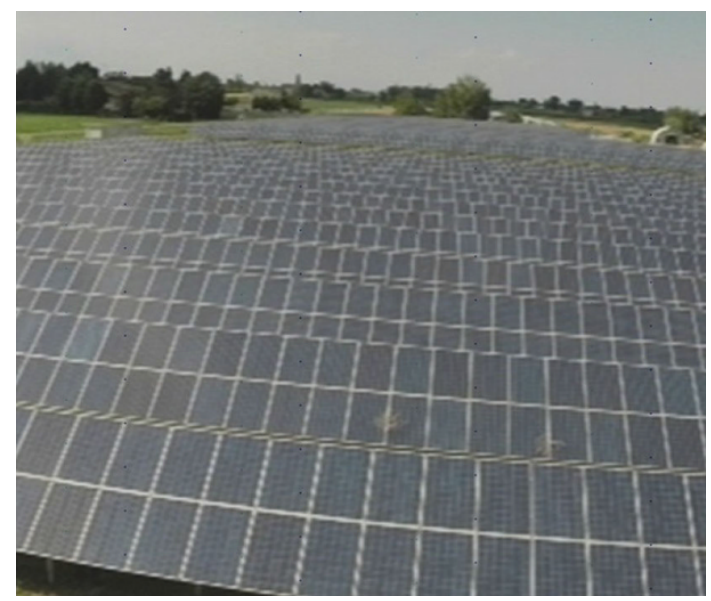

Fig. 3 PV plant in North of Italy

This PV plants integrates about 12,600 polycrystalline PV modules with tilt up to $30^{\circ}$ and facing to the south as shown in Fig. 3. The PV plant located in $48^{\circ} 50^{\prime}$ north and $11^{\circ} 07^{\prime}$ east. In addition, the PV plant is connected to the medium voltage (MV) grid by six inverters with total capacity of $3 \mathrm{MWp}$. This PV plant is subdivided to 3 sub-PV plants whichever can generate about $1 \mathrm{MWp}$ electricity approximately. In every PV sub-plants, many measurement sensors such as ambient temperature, solar radiation meter, and wind speed were installed to monitor the weather condition.

The ground size of inspected PV plants is almost $350 \times 120 \mathrm{~m}^{2}$.

Light UAV platform used for the experiment

Nimbus Company is one of the pioneer corporations in UAS technology in Italy, active in research and producing different kinds of UAV platforms. It is important to 


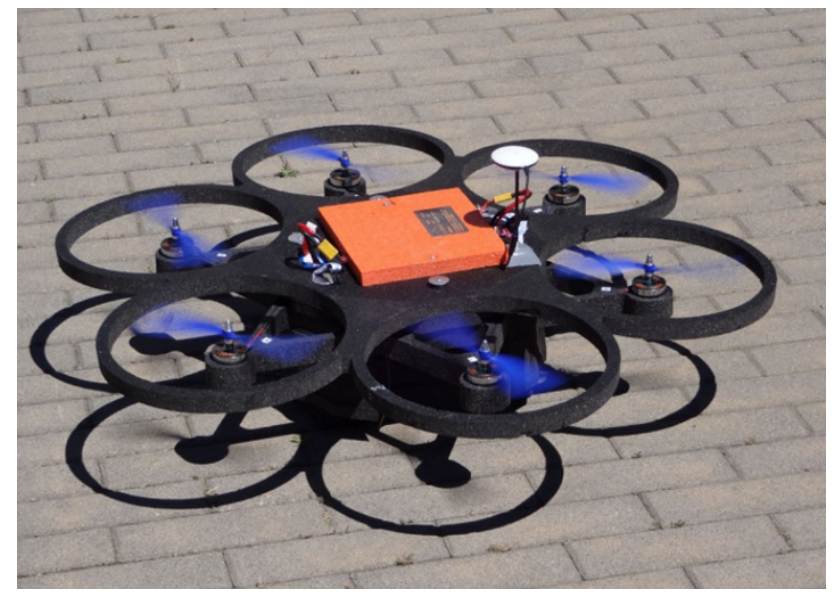

Fig. 4 Nimbus PPL-610 UAV platform

Table 1 UAV feature

\begin{tabular}{ll}
\hline Items & Nimbus PPL-610 \\
\hline Cruise Speed & $0-20 \mathrm{kts}$ \\
Operational range (regulation) & $1.25(0.25) \mathrm{Km}$ \\
Max altitude (regulation) & $150 \mathrm{~m}(70 \mathrm{~m})$ \\
Flight endurance & $0.25-0.4 \mathrm{~h}$ \\
Weight & $2.8 \mathrm{~kg}$ \\
Height & $0.25 \mathrm{~m}$ \\
Length & $(\varnothing) 0.98 \mathrm{~m}$ \\
Propulsion & Electric power \\
\hline
\end{tabular}

underline that Nimbus Company has already achieved multiple Permit to Fly from ENAC authority actively contributing to define regulation and procedures to obtain permission to fly in Italy for the light-UAV segment. In this investigation, PPL-610 UAV (Fig. 4) was employed to inspect the SolarTech lab and a real PV plant in north of Italy to detect any defect or failure of PV modules. Main characteristic of this machine is reported in Table 1.

Even if the cruise speed is limited for the considered light segment, one of the critical aspects for these machines to operate in real operative scenarios, especially in rural areas, is the UAV flight control and its reliability. In this light standard, GPS may suffer some trouble in satellite localization and it plays in any case an important role for the monitoring task. In fact, in great PV plants, the GPS can coordinate the inspection route mapping during PV modules monitoring process and in image post-processing or reconstruction.

\section{Monitoring devices and techniques}

There are different devices for inspection of energy generation equipment. Typically, PV systems monitoring can be carried out by high precision electro-optic sensors and

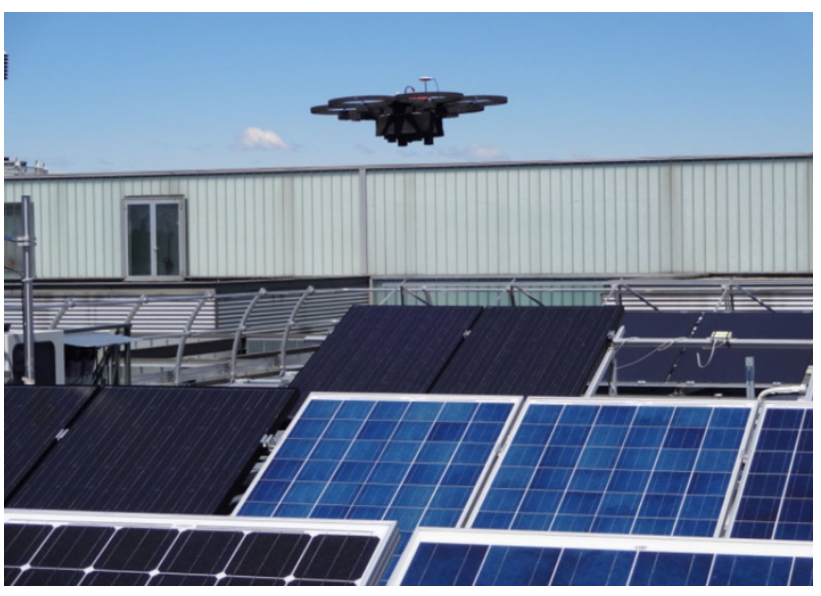

Fig. 5 PV modules inspection at Solar Tech Laboratory by Nimbus PPL-610 UAV platform

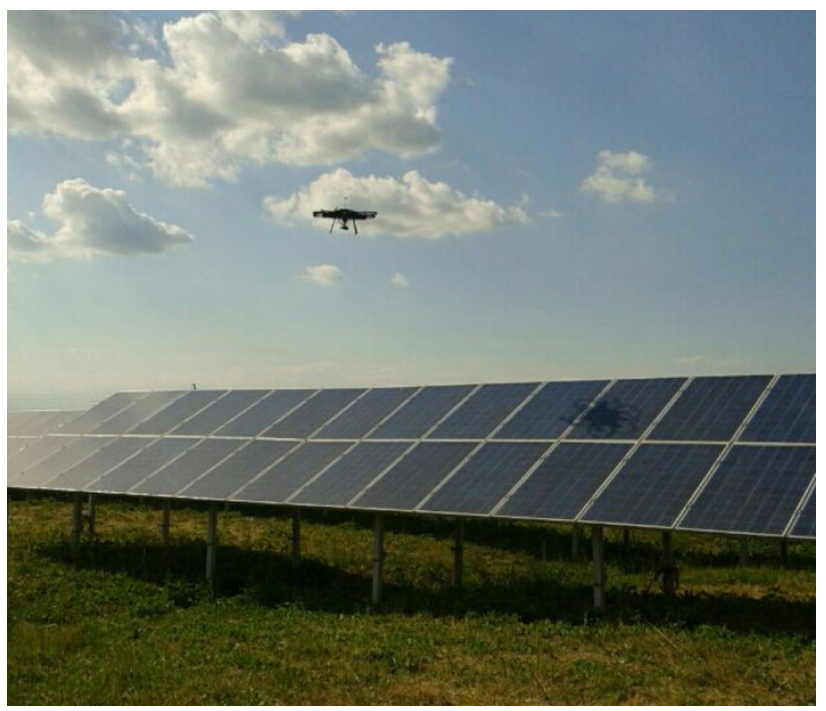

Fig. 6 PV modules inspection at PV plant in north of Italy by Nimbus PPL-610 UAV

high-resolution infrared cameras as well. In fact, these latter devices are useful to detect temperature regions in PV modules which may be affected by hot spot or snail trails [17]. Inspection devices help to find out defects and faults before degradation of PV modules and it leads to mitigate PV modules defects by early solution recommendation with expert engineers in this area. Nevertheless, the UAVs can carry various detector, sensor, and camera devices to inspect defects on the monitored energies systems [18].

Thermography analysis is the understanding of the temperature rate of photovoltaic modules surface. In this regards, utilization of thermal cameras can be useful to find out defects on photovoltaic modules. This inspection method is normally carried out during PV systems working period. Visual inspection is another method to detect PV 


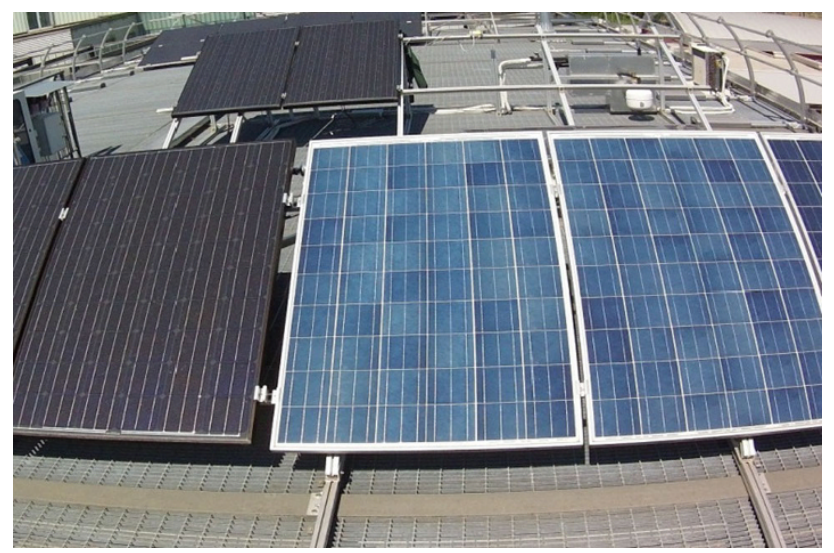

Fig. 7 Visual analysis of PV modules in Solar Tech Lab

modules failures. In this inspection method, the most external stresses can be observed on the PV modules [19]. Preliminary tests of inspection performed by NIMBUS PPL-610 UAV in Solar Tech Lab and a real plant are shown in Figs. 5 and 6 respectively.

\section{Preliminary results and discussion}

In this first experimental work, visual and thermal imaging cameras were mounted on PPL-610 UAV to capture the precise pictures and videos from PV modules in Solar Tech lab. In this case, the flight was performed in visual line of site and no GPS was used for route mapping. Thermal analysis can represent a reliable and fast scanning method to evaluate PV modules in terms of defects and faults. The duration of inspection time for monitoring whole solar tech labs' PV modules was took long just few minutes and was repeated in order to prove the method robustness.

In this test, the visual camera has been employed to capture pictures in visible range for overall perspective of PV plant. Visual picture of PV modules taken by NIMBUS PPL-610 UAV is shown in Fig. 7.

Thanks to the thermal camera; differences in temperature homogeneity could be observed for different PV modules due to degradation and manufacturing diversity. Figure 8 shows the thermal picture of PV modules captured by thermal camera during flight over Solar Tech lab. The $\mathrm{PV}$ modules have a very homogeneous behavior in term of their temperature.

Also in the second test, visual and thermal imaging cameras were mounted on PPL-610 UAV. In real large PV field (see Fig. 9), the route mapping is very crucial to have accurate data of PV modules status and it helps to reduce the mistake and prevent of any data missing during the PV plants monitoring. Nevertheless the inspection process

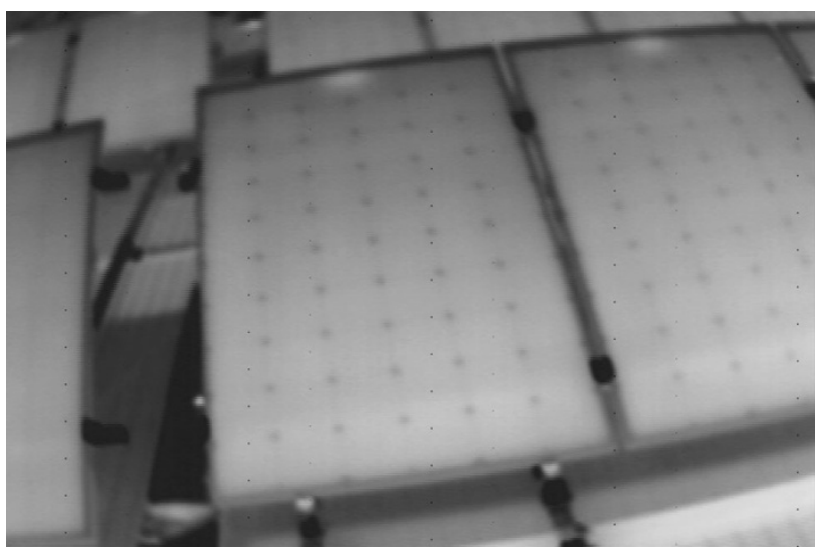

Fig. 8 Thermography of PV modules with UAS

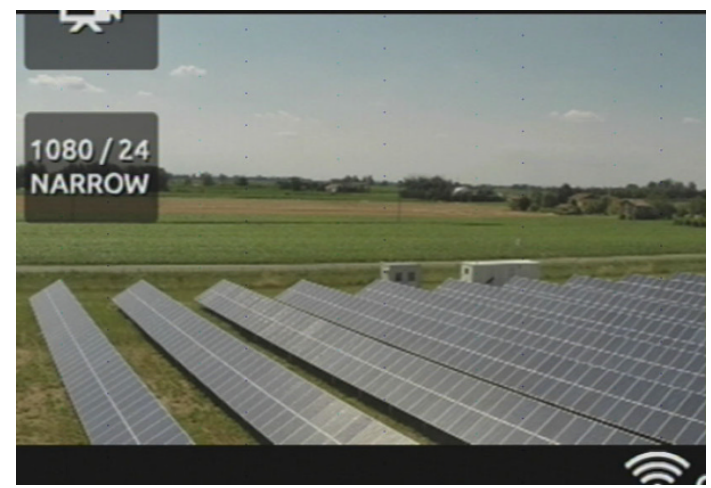

Fig. 9 Visual analysis of PV modules in PV plant in north of Italy

should be carried out carefully in terms of route mapping to optimize the PV modules monitoring in terms of cost and time.

Typically, the route mapping for each PV plants can be different in inspection process of PV modules by UAV with respect to the PV plants shape. Therefore, it can be carried out whether vertical or horizontal.

In present experimental work, the inspection procedure of PV modules was carried out through two different route mappings (horizontal and vertical) to find out the optimum monitoring way.

According to Fig. 10, picture A and B show the horizontal and vertical route mapping of PV modules inspection by UAS, respectively. In PV modules monitoring route $\mathrm{A}$, the total travelled distances are around $2.71 \mathrm{~km}$ and while it is just $2.02 \mathrm{~km}$ for PV modules inspection in route B. In fact, in horizontal way, the distance between each line is around $8 \mathrm{~m}$ and in vertical way is around $10 \mathrm{~m}$.

With this regards, the results show that the vertical route inspection is more effective, faster and cost efficient due to the travelled distances by UAS is less. However, it should be mentioned that in vertical way, if the UAS fly is at higher altitude, it can cover and monitor more PV modules. 


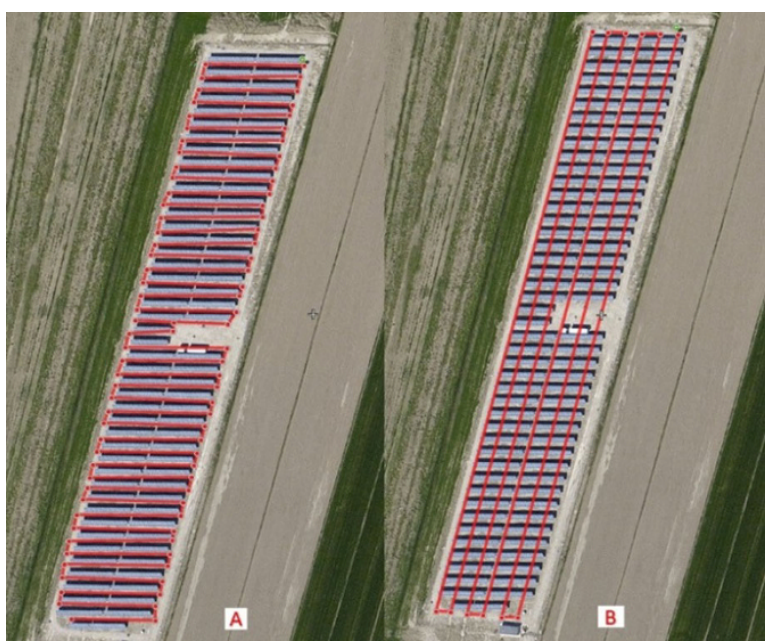

Fig. 10 Horizontal and vertical inspection route mapping by UAS in PV plant in north Italy

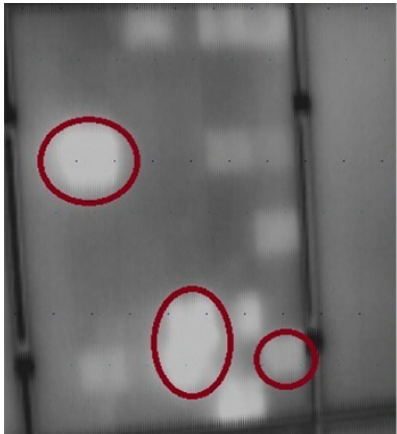

(a)

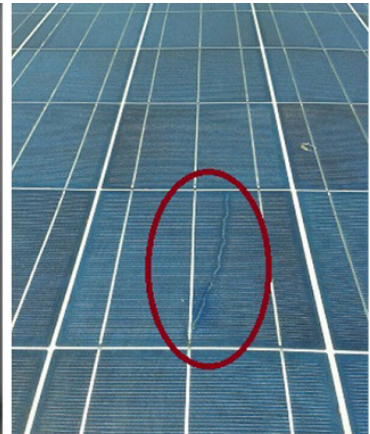

(b)
Fig. 11 a Thermographic analysis of a mono-crystalline module captured by Nimbus PPL-610 UAV. b Picture captured by Nikon camera with a PV module affected likely by corrosion
Nevertheless, more accurate sensors and cameras are needed if UAS should fly at higher altitude since for the collection of precision data, the UAS must fly at low altitude and close to PV modules.

Figure 11 illustrates some defects on the PV module which is captured by UAS in real plant. Thermal analysis helped to find out hot spot, micro-crack and shadowing on PV modules (Fig. 11a). In addition, visual analysis was led to understanding defects such as snail trails, delamination, bubbles, cracking, and brunt cell. Figure $11 \mathrm{~b}$ shows a PV module affected by crack defect.

By using UAV, it is possible to recognize PV-modules that could have lower performances using both visible and IR images. Thus, direct monitoring performed by UAVs can reach higher performances by flying and hovering at low altitude and low speed by using different cameras and sensors mounted onboard.

However, it should be emphasized that the visual and thermal or infrared inspections are not sufficient alone to perfectly understand PV systems problems, hence further information are required to assure and define correct reason of that particular PV system fault. Therefore, it must be tested electrically as well. Figure 12 shows the resulting electrical performance degradation in some Solar Tech lab PV modules previously detected by the UAV survey.

Thus, all these defects play a crucial role in overall system performances. PV Plants' lifetime is very dependent on the appropriate maintenance and inspection operations. With the proposed method, it is possible to rapidly evaluate the number of PV modules that are considered underperforming receiving a useful feedback on future replacement policies.
Fig. 12 Comparison of measured power performances of different PV modules affected by snail trails phenomena defects

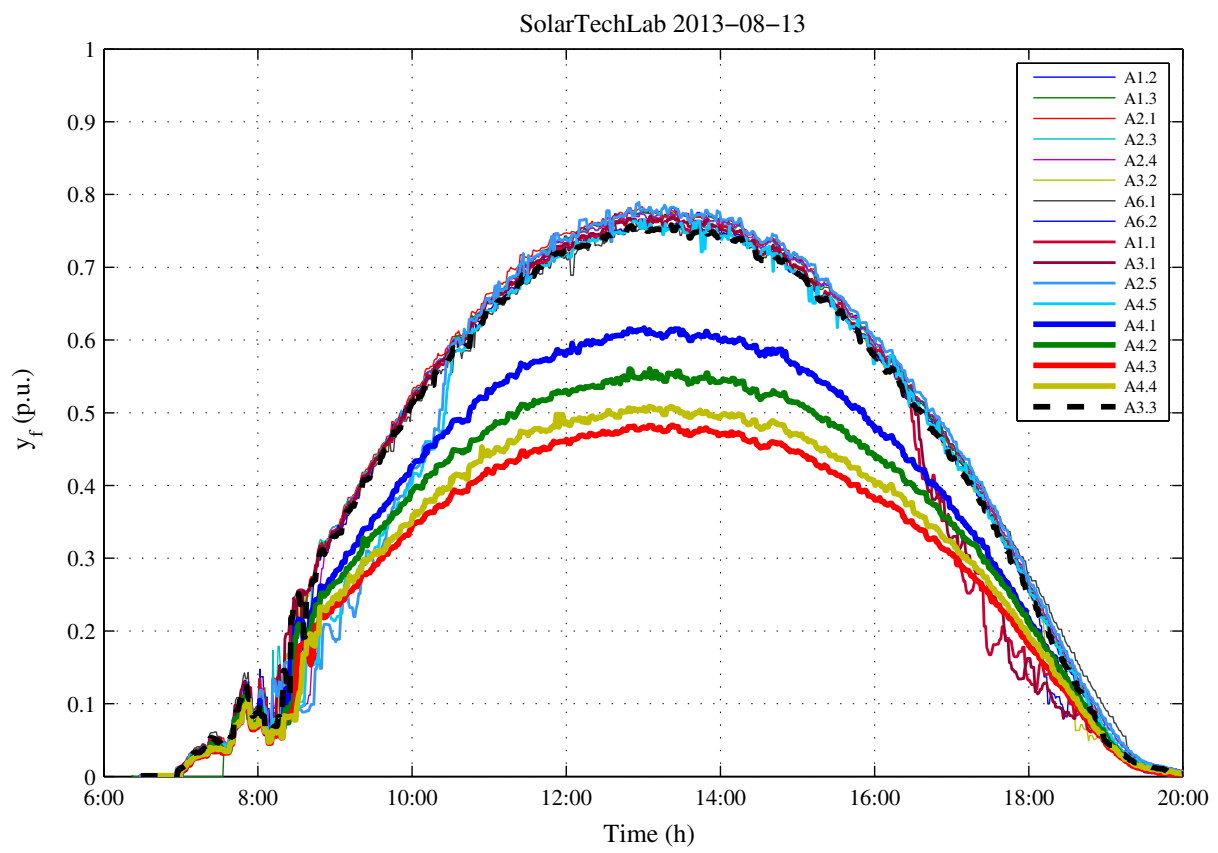


Regarding PV plants' diffusion, they are going to increase over the coming decades, thus operation and maintenance of PV systems become essential. The highest level of performance will be obtained utilizing reliable and effective monitoring service with reasonable cost.

According to our preliminary experimental analysis, using UAS technology in PV plant monitoring could be cost effective and it can contribute to save inspection time. In current research, our target PV plant capacity was around $1 \mathrm{MW}$. The standard operation and maintenance annual cost for this size plant (taking into account scheduled maintenance/cleaning, unscheduled maintenance, inverter replacement, reserve and insuranceproperty taxes) is around $50 \$$ per $\mathrm{kW}$. With this regards, it is possible to estimate that if the UAS is used to inspect such solar systems, the additional cost can be around 6-10\% of annual maintenance cost, with much more benefit on the increasing the overall performance of the plant.

\section{Conclusion}

Light UAVs have many advantages in monitoring operations such as cost effectiveness, safety, fast detection, light weight, and the fact that large amount of data can be collected by various sensors and cameras at the same time. In current investigation, a light UAV has been employed with different sensors onboard to monitor PV modules performances both in visible and IR spectrum.

A novel concept to contribute to UAVs application in PV plant inspection is here proposed at a small scale, but extensible for large scale, in order to optimize maintenance operations and assure a more accurate performance monitoring during all the entire plant life. Furthermore, UAVs application in PV plants can guarantee to increase overall system performance.

Open Access This article is distributed under the terms of the Creative Commons Attribution License which permits any use, distribution, and reproduction in any medium, provided the original author(s) and the source are credited.

\section{References}

1. Sullivan, G., Pugh, R., Melendez, A., Hunt, W.: Operations and Maintenance Best Practices-A Guide to Achieving Operational Efficiency (Release 3). Pacific Northwest National Laboratory (PNNL), Richland (2010)

2. Trancossi, M.: Testing performance, weathering and aging of photovoltaic modules. In: ASME 2011 5th International Conference on Energy Sustainability, 2011, pp. 1375-1382
3. Nonami, K.: Prospect and recent research and development for civil use autonomous unmanned aircraft as UAV and MAV. J. Syst. Des. Dyn. 1, 120-128 (2007)

4. Antonio, P., Grimaccia,F., Mussetta, M.: Architecture and Methods for Innovative Heterogeneous Wireless Sensor Network Applications. Remote Sensing (ISSN 2072-4292), 2012, 4, pp. 1146-1161

5. Trost, L.C.: Unmanned air vehicles (UAVs) for cooperative monitoring: Sandia National Laboratories, 2000

6. Ozuncer, D., Speijker, L., Stoop, J., Curran, R.: Development of a safety assessment methodology for the risk of collision of an unmanned aircraft system with the ground. Training 2013, 11-25 (2011)

7. Hausamann, D., Zirnig, W., Schreier, G.: Monitoring of gas transmission pipelines-a customer driven civil UAV application. In: ODAS Conference, 2003

8. Sampedro, C., Martinez, C., Chauhan, A., Campoy, P.: A supervised approach to electric tower detection and classification for power line inspection. In: 2014 International Joint Conference on Neural Networks (IJCNN), pp. 1970-1977. 6-11 July 2014

9. Montambault, S., Pouliot, N.: The HQ LineROVer: contributing to innovation in transmission line maintenance. In: 2003 IEEE 10th International Conference on Transmission and Distribution Construction, Operation and Live-Line Maintenance, 2003, IEEE ESMO, pp. 33-40

10. Neri, M., Campi, A., Suffritti, R., Grimaccia, F., Sinogas, P., Guye, O., Papin, C., Michalareas, T., Gazdag, L., Rakkolainen, T.: UAV-based capturing of HD/3D content with WSN augmentation for immersive media experiences. In: IEEE International Conference on Multimedia and Expo, pp. 1-6 (2011)

11. Grimaccia, F., Bellezza Quarter, P.: Hybrid UAS for HD-3D multimedia system for entertainment purposes. In: Proceedings of AUVSI Unmanned Systems North America, 2011, ISBN: 978-161839-348-7, pp. 90-94

12. Bellezza Quater, P., Grimaccia, F., Leva, S., Mussetta, M., Aghaei, M.: Light unmanned aerial vehicles (UAVs) for cooperative inspection of PV plants. IEEE J. Photovolt. 4(4), 1107-1113 (2014)

13. Eisenbeiss, H.: A mini unmanned aerial vehicle (UAV): system overview and image acquisition. International Archives of Photogrammetry. Remote Sensing and Spatial Information Sciences, vol. 36,2004

14. Dalamagkidis, K., Valavanis, K.P., Piegl, L.A.: On unmanned aircraft systems issues, challenges and operational restrictions preventing integration into the National Airspace System. Prog. Aerosp. Sci. 44(7-8), 503-519 (2008)

15. ENAC- Remotely Piloted Aerial Vehicles Regulation, Edition No. 1, 16.12.2013

16. Dolara, A., Lazaroiu, G.C., Leva, S., Manzolini, G.: Experimental investigation of partial shading scenarios on PV (photovoltaic) modules. Energy 55, 466-475 (2013)

17. Dolara, A., Leva, S., Manzolini, G., Ogliari, E.: Investigation on performance decay on photovoltaic modules: snail trails and cell microcracks. IEEE J. Photovolt. 4(5), 1204-1211 (2014)

18. Strnadel, J., Gvritishvili, R., Vanek, J.: Comparison between visual and thermovision inspection of PV field. In: 28th European Photovoltaic Solar Energy Conference and Exhibition, 2013

19. Vanek, J., Strnadel, J., Gvritishvili, R.: Influence of snail tracks phenomenon on photovoltaic modules operation. In: 28th European Photovoltaic Solar Energy Conference and Exhibition, 2013 